\title{
Fotografia, pintura e performance na arte contemporânea: um estudo sobre a obra de Helena Almeida ${ }^{1}$
}

\author{
Laila Algaves Nuñez \\ Pontifícia Universidade Católica do Rio de Janeiro - PUC-Rio \\ Departamento de Comunicação Social - Bacharelado em Cinema
}

\section{Resumo}

O presente estudo busca compreender de que maneira a arte contemporânea produziu novos e complexos modelos e suportes de representação. Nesse contexto, a fotografia e a performance - pensadas a todo momento em confronto com a tradição da pintura - aparecem como as formas de arte fundamentais da contemporaneidade, transfigurando o próprio estatuto da imagem hoje. O caso da artista portuguesa Helena Almeida, nesse sentido, é aqui analisado como exemplar para esta discussão, levantando questões acerca da essência do pictórico, da hibridez entre técnicas artísticas e a representação - ou exibição - do corpo feminino no espaço da arte.

Palavras-chave: arte contemporânea; fotografia; pintura; performance; Helena Almeida.

\section{Introdução}

Embora muito se discuta sobre o caráter fragmentário e dispersivo da produção artística contemporânea, a história e o sistema da arte, pronta e inevitavelmente, delimitam categorias de identificação que os amparem. Em geral, o novo vocabulário que integra a rede semântica da arte contemporânea inclui termos como happenings, performances, arte corporal e instalações multimídias. Ainda assim, algumas obras - ou mesmo todo um conjunto de obras de determinado artista - insistem em escapar às classificações que, embora pareçam agora mais fluidas, ainda são, em certa medida, estanques e limitadoras.

Helena Almeida, artista visual portuguesa, é um desses casos de difícil definição. Mesmo inserida no contexto da arte moderna e contemporânea, fundou uma linguagem plástica própria, que transita entre as fronteiras da fotografia, da pintura e da performance, sem, no entanto, reduzir-se a nenhuma delas. Sua originalidade a aproxima e a distancia, ao mesmo tempo, da produção portuguesa e ocidental da época, conduzindo, a partir de um olhar

${ }^{1}$ Artigo derivado de monografia de graduação em Cinema, orientada pela professora Tatiana Siciliano, e entregue em dezembro de 2019. 
feminino e singular, a discussão sobre os paradigmas de representação do pictórico e sua nova materialidade. "Não era pintora, não era escultora, não era fotógrafa, não era performer, não era videasta: era tudo isso, ora simultaneamente, ora alternadamente"2.

$\mathrm{Na}$ tentativa de compreender os temas presentes e os problemas colocados pelo trabalho de Helena, é preciso, antes, reconhecer alguns aspectos que parecem ser consensualmente identificados como fundamentos da arte do pós-anos 1960 - Henri-Pierre Jeudy (2002), sociólogo e professor de estética francês, reúne essas características em três principais questões em seu livro O Corpo como Objeto de Arte: a desinibição, a supervisibilidade e a superconceituação (2002, p. 145). A princípio, o estudo por ele proposto é de cunho quase antropológico, mais preocupado com o diagnóstico cultural de um tempo específico que com uma análise crítica da história da arte. Por outro lado, Ferreira Gullar (2003), em Argumentação Contra a Morte da Arte, desenvolve, em tom bastante grave, essas particularidades que diferem e apartam a arte contemporânea do que comumente se entende - ou se entendia - por arte.

Em síntese, o poeta examina o caminho percorrido pela tradição artística em um gradativo afastamento do mimético em direção à descoberta do suporte e da atribuição de expressividade às formas - ganham nova materialidade a cor, a linha, o contorno, o pigmento e, em última instância, a própria tela. O artista, diante das possibilidades que agora se apresentam, passa a gozar de uma infinita e arbitrária liberdade para conferir significados. 0 fundamento da crítica de Gullar reside na ideia de que isto resultaria, necessariamente, em um esgarçamento do sistema de códigos e símbolos constitutivo da arte, o que não pode levá-la a outro fim senão a sua deslegitimação e ocaso.

Argumentação Contra a Morte da Arte (2003) - seguindo as teses de Walter Benjamin (1955) em seu texto $A$ obra de arte na época de sua reprodutibilidade técnica - não contempla o surgimento da fotografia e do cinema como parte do sistema canônico e tradicional da arte; ao contrário, os situam como processos tecnológicos signos de uma modernidade determinante para a queda ou a reconfiguração desse sistema. São considerados meios de reprodução mecânica, a máquina anunciaria que não há mais espaço para o artista artesão: em tempos de largos avanços industriais, as sofisticadíssimas invenções do século tornariam banais quaisquer manifestações individuais de arte.

\footnotetext{
${ }^{2}$ GOMES, Filipa; RODRIGUES, Cristiana; MENDONÇA, Ricardo. Helena Almeida - Era uma vez uma mulher sem sombra que encontrou uma. Publicação para Faculdade de Belas-Artes da Universidade de Lisboa, Lisboa, maio de 2006. Texto disponível em: <http://www.arte.com.pt/text/filipag/helenaalmeida.pdf>. Acesso em: 26 ago. 2018.
} 
Mesmo quando a fotografia passa a ser gradativamente integrada ao circuito das belas artes, suas particularidades técnicas e estéticas - bastante desenvolvidas pelos filósofos Philippe Dubois (2012) e Roland Barthes (1984) em suas canônicas obras $O$ ato fotográfico e $A$ câmara clara, respectivamente - parecem suprimidas em prol de uma aproximação às tradicionais e já consolidadas formas de arte. Nesse processo, a fotografia, até hoje compreendida como a antítese da pintura, ou aquela que a libertou para o caminho do abstracionismo, acabou por importar dessas outras técnicas e ofícios as suas bases de análise e de avaliação.

No entanto, no contexto contemporâneo, a fotografia e a imagem técnica dão lugar a uma nova possibilidade expressiva. Na contramão do que propõe Baudelaire, que define a arte como "aquilo mesmo que permite escapar do real" (DUBOIS, 2012, p. 30), o ato estético, hoje, se confunde com o próprio agir no mundo. Em tempos em que a motivação de grande parte das manifestações artísticas parece fugir à trilogia "espelho-ordem simbólica-sistema moral" (JEUDY, 2002, p. 120), a fotografia e, certamente também, a performance aparecem como caminhos para a restituição, na imediatidade do real, de toda a riqueza de potências do corpo antes da imposição restritiva da linguagem.

Helena Almeida, cuja carreira se estende desde os anos 1960 até meados dos anos 2000, está inserida neste efervescente momento das artes e não deixa, portanto, de pensar sobre todas essas questões relativas a um suposto essencial pictórico, aos inéditos discursos artísticos da época e a seu próprio corpo, enquanto artista e mulher. Nascida em 1934, Helena é filha de um importante escultor do modernismo português, autor de grande parte da estatuária oficial implementada pelo ditador Salazar, Leopoldo de Almeida. Em 1955, forma-se pela Escola Superior de Belas Artes de Lisboa e conquista, em 1964 - já casada com o arquiteto Artur Rosa e mãe de dois filhos -, uma bolsa de estudos em Paris.

Lá, tomará contato com grandes obras da arte abstrata, cujos preceitos de liberdade de representação influenciarão toda a sua criação plástica. Sua primeira exposição individual será realizada em 1967, na Galeria Buchholz, apenas cinco anos depois da obra fotográfica Sautdansle vide (Salto no vazio), de Yves Klein - para muitos o precursor da arte da performance. Nessa pequena primeira mostra, Helena Almeida já indicava os problemas que permeariam todas as fases de seu trabalho, colocando em xeque os limites formais da pintura e da tela e estudando a própria imagem como partícipe da obra. 


\section{A desestabilização do ente pictórico}

Em suas primeiras exposições, o objeto tela é, mais explicitamente, o locus primordial para a pesquisa da artista. Em obras como Sem Título (1969) e Sem Título (1968) (Figura 1), Helena evoca a tridimensionalidade da pintura, o suporte pelo qual a imagem pode existir - ou que é, ele mesmo, parte dela. Desvela, então, a ilusão do quadro como "janela para o mundo", que "tão pertinentemente traduzira as aspirações do pictórico desde o Renascimento. A 'janela para o mundo' torna-se, assim, uma janela 'cega'"' (BRAZ, 2007, p. 27).

FIGURA 1 - Sem Título (1969), à esquerda, e Sem Título (1968), à direita.

Ambas de $130 \times 97 \mathrm{~cm}$.
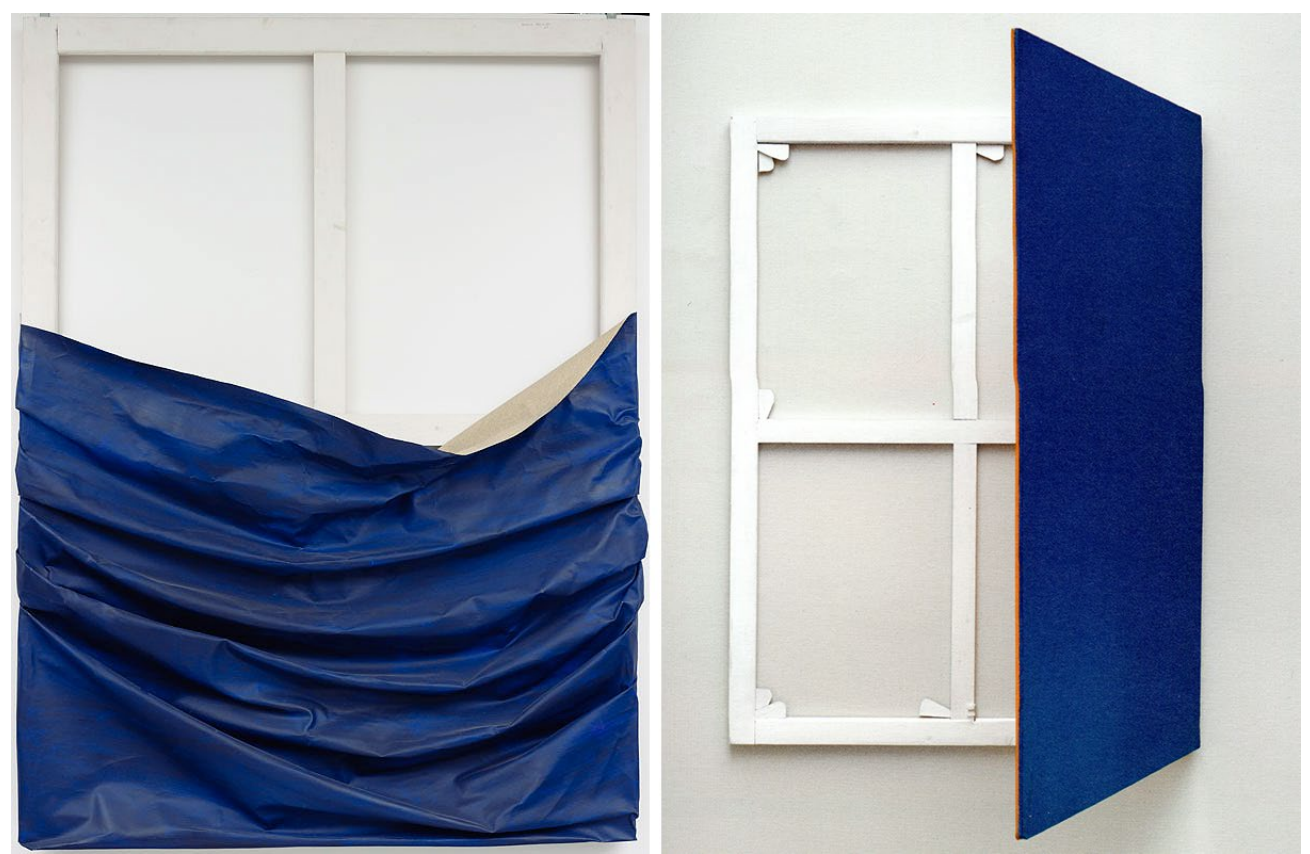

Fonte: Imagens escaneadas de A minha obra é o meu corpo. Catálogo organizado para exposição no Museu de Arte Contemporânea Serralves. Porto: 2015.

A pintura, então, pode ser entendida como uma "veste destinada a cobrir um corpo imaterial, o corpo da arte ela mesma, em si irrepresentável" (ALMEIDA, 2015, p. 22). É como se a tela cedesse ao próprio peso e se deslocasse, então, do plano à escultura. Aqui, já começa a se desenhar o mecanismo que Helena vai sempre utilizar em suas obras: a ausência do pictórico stricto sensu, sempre apenas implícito ou insinuado, como forma de mantê-lo sempre em tensão, em potência. 
Braz (2007) desenvolve essa questão nos trabalhos da artista pela própria noção de desenho, que aparecerá com cada vez mais frequência na produção artística de Helena a partir do final da década de 1960 e início dos anos 1970 - marcando exatamente a sua transição para o recurso fotográfico. O termo "desenhar", cuja origem etimológica provém do latim designare, remete, ao mesmo tempo, para a ação de traçar e para a ação de designar. Seu significado está, portanto, duplamente associado à ideia de apontar, indicar.

Implica, assim, o vestígio de uma mobilidade que torna presente a dimensão do desejo. Mas o movimento é sempre provisório na medida em que deseja uma forma na qual a mobilidade cessa e o traço transforma-se em limite ou contorno, estabelecendo diferenças (figura/fundo) onde esse mesmo desejo arrefece. (BRAZ, 2007, p. 32)

Trata-se, então, de impor um limite não-limitante - por mais ilógico que possa parecer, as contradições coexistem em suas obras. Nesse sentido, Braz escreve sobre a "qualqueridade" da pintura a que Helena Almeida parece chegar. Valendo-se das teorias de Giorgio Agamben, filósofo italiano, Braz identifica a busca da artista pela especificidade da pintura justamente à descoberta de sua propriedade genérica. Segundo o autor, o "qualquer" é equivalente ao gesto do amante, cujo desejo não depende de uma ou outra característica do amado, não pretere uma qualidade à outra. Em outras palavras, é "o ser com todas as possibilidades, sem que nenhuma o determine e sem cair na indeterminação; ou seja, o ser com todas as suas ligações, pois só a totalidade destas constituem o seu modo de ser como é" (BRAZ, 2007, p. 34).

Na pintura genérica, ao contrário de uma "pintura específica" - aquela que se resguarda nas noções tradicionais sobre o pictórico e se alicerça sobre um conjunto de relações rígidas entre artista, obra e público -, não se pode pensar em demarcações precisas de espaço e tempo: os limites da tela se afrouxam; as diferenças entre figura/fundo e exterior/interior se embaçam; criador e espectador alternam lugares e funções. Mesmo a "temporalidade deixa de coincidir com o 'antes' e 'depois' convencionais". Em Helena Almeida, o tempo do pictórico "contém todo o passado e todo o futuro de cada pintura" (BRAZ, 2007, p. 101).

\section{Fotografia ou pintura?}

É neste momento, ao descrever as transformações que as obras da artista encerram sobre o "fazer específico" da pintura, que Braz menciona, pela primeira vez, o uso da fotografia em seus trabalhos. Embora já tivesse aparecido em obras no início de sua carreira, é a partir de 1975 que Helena incorpora, com mais força e constância, o registro fotográfico a suas peças - 
que o autor, ainda assim, denominaria de pinturas. Trata-se de um processo de redução ao mínimo, que, levado ao cabo, resultaria na eliminação da própria tela: "Já não há cavalete, nem nada, há eu a pintar para a frente" (ALMEIDA, 2015, p. 132), diz a artista em entrevista à Marta Moreira de Almeida e João Ribas.

O campo pictórico, de forma extremamente inovadora, se projeta, então, para o espaço do espectador. Nas séries Pintura Habitada (Figura 2), de 1976, e Desenho Habitado (Figura 3), de 1975, o que se vê não é mais a pintura ou o desenho, mas, sim, a pintora a produzir, como se o quadro fosse, na verdade, um painel de vidro. Desloca-se, portanto, o próprio lugar da autoria, que deixa de estar presente apenas pela assinatura do artista - com Helena, o "sujeito da obra" torna-se "sujeito na obra" (BRAZ, 2007, p. 59), e o ato fundante da peça é a peça ela mesma.

FIGURA 2 - Pintura Habitada (1976). Série de 7 fotografias 46x40cm.
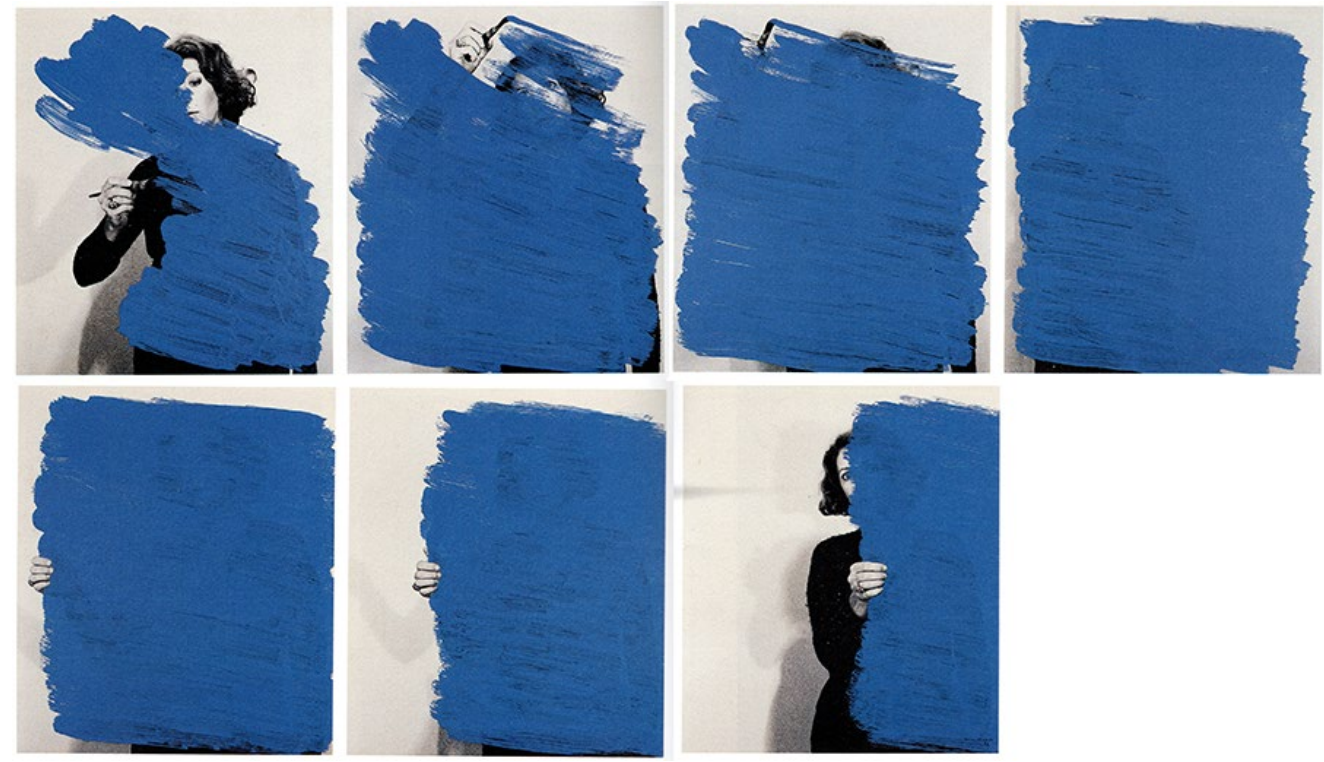

Fonte: Imagens escaneadas de $A$ minha obra é o meu corpo. Catálogo organizado para exposição no Museu de Arte Contemporânea Serralves. Porto: 2015. 
FIGURA 3 - Desenho Habitado (1975). Dimensões variadas (2 de 8 elementos).

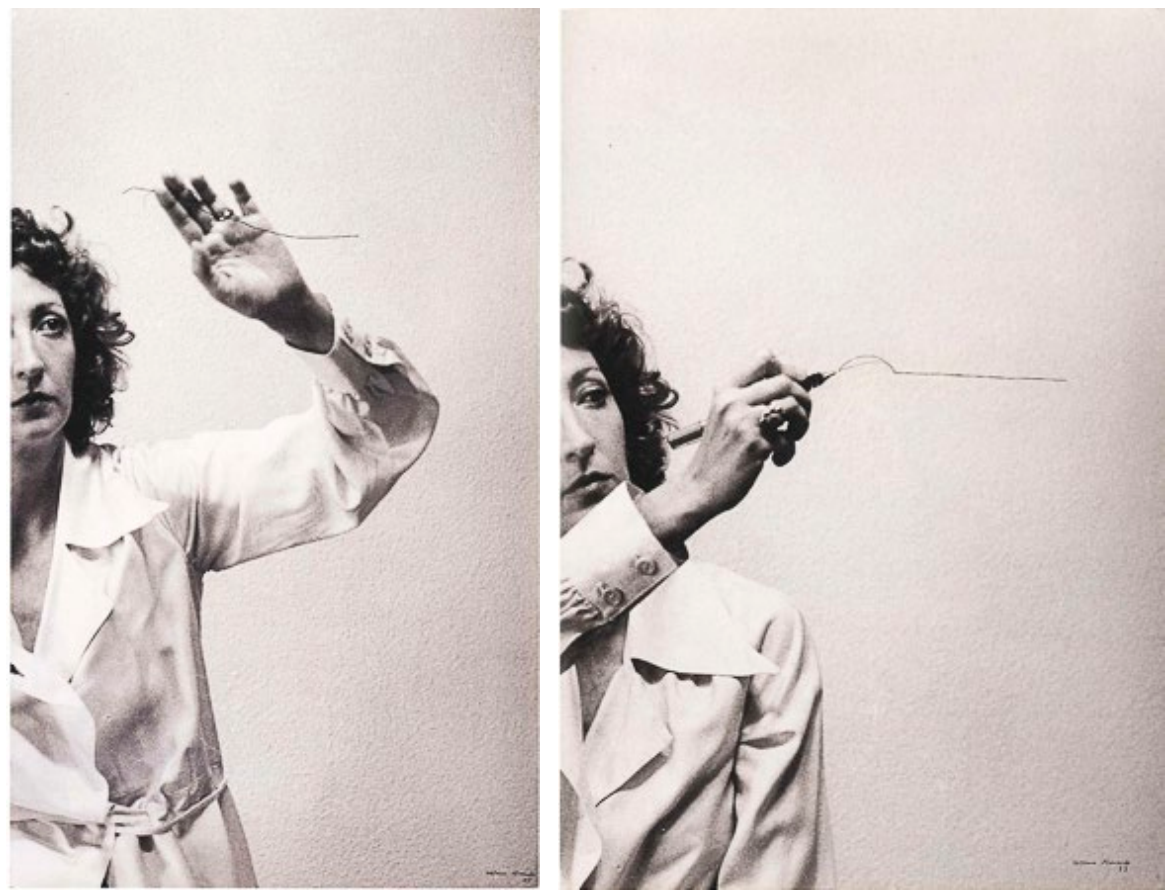

Fonte: Imagens escaneadas de A minha obra é o meu corpo. Catálogo organizado para exposição no Museu de Arte Contemporânea Serralves. Porto: 2015.

Braz - embora não reconheça que as fotografias, nesse caso, constituem autorretratos refere-se ao uso do fotográfico como o meio possível de tal efeito; afinal, é apenas através da fotografia que se pode representar-se enquanto representa. A mão que pinta jamais poderá pintar-se pintando porque, para isso, deveria imobilizar a sua sombra e, consequentemente, pararia também o movimento de pintar. Nesse sentido, interessa debater a importância da fotografia no trabalho de Helena Almeida, revisitando as teorias que normalmente a relegam a um papel secundário.

$\mathrm{Na}$ esteira das ideias de Braz, as fotografias de Helena constituem mesmo registros documentais, testemunhos, que têm a função primeira de fixar a ação de pintar. O estatuto dessa fotografia muda, porém, se considerarmos que a cena em questão foi arquitetada de modo a produzir determinada imagem, e que, desde o início, estava destinada a ser capturada pela câmera. A obra, então, não pode existir sem a fotografia - da mesma forma que não pode prescindir da tinta ou da linha.

Quando Braz permanece a nomear as peças de Helena Almeida como pinturas, e não como "fotografias intervencionadas" (BRAZ, 2007, p. 102), está a destacar uma dimensão da 
pesquisa pictórica importantíssima em seu trabalho. Entretanto, está, também, a reduzir suas potencialidades. Em se tratando de um trabalho que busca, justamente, anular as hierarquias e desestabilizar as funções convencionais de uma obra de arte, é incoerente afirmar que um ou outro dispositivo é mais ou menos relevante para a composição final da peça. Muito mais interessante é, ao contrário, reconhecer como a artista logra produzir uma extensão de obras que escapam do atestado único e sólido da pintura, da fotografia, do desenho ou da performance, sendo ao mesmo tempo todas e nenhuma delas.

\section{Autorretrato e fotoperformance}

Em se tratando ainda das potencialidades do fotográfico, no caso de Helena, é preciso discutir, também, a dimensão do autorretrato presente em suas obras. Para aqueles que estudam o seu trabalho, na verdade, a ideia de que suas peças constituem algum tipo de observação acerca de seu próprio corpo é, quase sempre, rechaçada. Como mesmo indicado pelos títulos de algumas de suas mais relevantes séries, o movimento de Helena é o de habitar a tela, fundir-se à obra. Entre 2015 e 2016, uma exposição a ela dedicada na Fundição Serralves (Porto, Portugal) foi nomeada a partir do que a artista mesmo afirmava: A Minha Obra é o Meu Corpo, O Meu Corpo é a Minha Obra.

É exatamente por isso que, segundo estudiosos como Braz (2007), a presença de Helena no quadro estaria a serviço de uma investigação que permanece centralizada sobre o pictórico, jamais desviando-se para si mesma. O corpo da mulher, ali, não é o corpo próprio. Não possui nome e sobrenome. É, antes e, sobretudo, o corpo da pintura. Para o autor, admitir que as obras de Helena equivalem, sim, a autorretratos, seria incompatível com o seu empreendimento de anular a autoridade do "sujeito da obra", motivo pelo qual coloca-se dentro dela. Seria como "se o corpo se substituísse à assinatura, anulando o deferimento hierárquico que esta pressupunha" (BRAZ, 2007, p. 111).

Além disso, seu rosto - por excelência, o local privilegiado da individuação - surge em suas obras "frequentemente obliterado, desfocado, decomposto, ou simplesmente ausente, de tal forma que deixa de ser um lugar seguro" (BRAZ, 2007, p. 61). Trata-se, portanto, de um gesto de desarticulação, de desorganização da identidade - o que, segundo o autor, denotaria o desinteresse da artista pela representação de si e inviabilizaria a existência de um autorretrato. 
No entanto, Braz mesmo descreve o corpo de Helena como - da mesma forma que sua pintura - genérico. Este conceito, que corresponde à ideia de "qualqueridade", permite pensar em algo que esteja exatamente no meio entre a determinação e a indeterminação - ou, em outras palavras, entre a identidade e a sua omissão. Não se deve, portanto, apagar, prontamente, esta face de suas obras - isso, sim, seria incoerente com o desejo desestabilizador de Helena. Estudos como Dentro de mim (1998) e Dentro de mim (2001) (Figura 4), para além de uma experimentação sobre corpo e espaço, denotam uma expressividade tal que somente a artista, ela mesma, abrindo-se a total vulnerabilidade e exposição, poderia alcançar.

FIGURA 4 - Dentro de mim (1998), à esquerda, e Dentro de mim (2001), à direita.

Dimensões variadas.
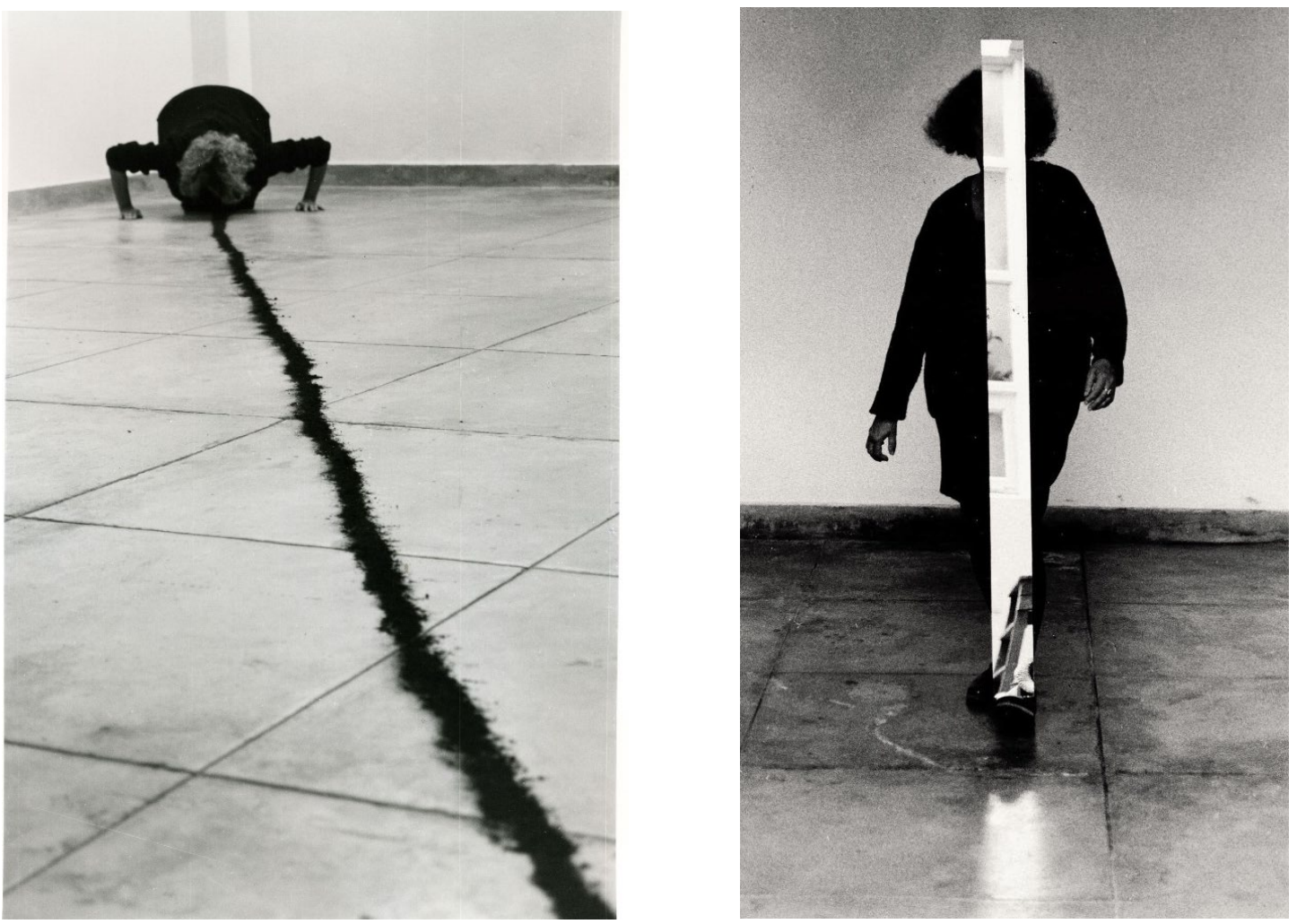

Fonte: Imagens escaneadas de A minha obra é o meu corpo. Catálogo organizado para exposição no Museu de Arte Contemporânea Serralves. Porto: 2015.

Mais uma vez, a originalidade de Helena é o situar-se no espaço entre os polos: ao mesmo tempo que se inscreve em cena e doa o seu corpo à obra - inscrevendo-se, portanto, na ordem da representação, da linguagem e do artificial -, também parece realizar estudos quase que anatômicos, em que a apresentação pura e objetiva de seu corpo como um objeto, como algo "impessoal", também está presente. Talvez por isso suas fotografias causem um efeito 
tão singular em quem as observa - a todo momento, como que em rápida e contínua alternância, oscilamos entre a identificação e a empatia, e o afastamento e a contemplação.

Não se poderia deixar de lado, portanto, a dimensão extremamente performativa de suas obras. Embora mais explicitamente manifesta em seus trabalhos a partir de 1974 - quando o corpo aparece como elemento mais forte e constante -, autores como Bernardo Pinto de Almeida (2015) localizam a performance em trabalhos bem mais antigos na carreira de Helena. Quadros aqui anteriormente citados (ver Figura 1) já estariam a evocar o movimento, a ação, como se a própria tela ou a moldura estivessem a performar para o espectador. Em certa medida, pode-se considerar que se trata da mesma ordem de impressão do urinol, de Marcel Duchamp.

Quando, para a História da Arte, performance se torna quase sinônimo de bodyart, passa-se a considerar performativo tudo aquilo que é, ao mesmo tempo, produto do corpo e da ação ambos como paradigmas contemporâneos de uma arte que se quer presentificada, que não admite fixar-se nos museus ou nas galerias. No entanto, Regina Melim (2008), em seu livro Performance nas Artes Visuais, propõe uma definição mais ampla para "performance" a partir do estudo de obras de artistas estrangeiros e brasileiros.

Entre eles, a autora cita o caso de Laura Lima, cujo corpo nunca está presente em seus trabalhos. Em vez disso, coloca em cena o corpo de outras pessoas - ou, ainda, de animais -, em uma ação que, no lugar de "performance", prefere chamar de "Instância". Da mesma forma, descreve obras de Hélio Oiticica e Lygia Clark, "diante das quais o espectador era sempre solicitado a usá-las ou manipulá-las, pois a mera contemplação não bastava para revelar seu sentido" (2008, p. 57).

Regina destaca, então, o papel do artista como propositor de ações - não, necessariamente, a serem executadas por ele mesmo, mas, sim, pelo espectador-participador. Mais do que performance, cabe pensar em um espaço de performação ou, como definiria Hélio Oiticica, um "espaço poético tátil" (MELIM, 2008, p. 24). A partir do alargamento do significado do termo, começa-se a considerar também performática a ação "sem audiência", que acontece para o olhar da câmera fotográfica ou de vídeo. Nesses casos, assim como em qualquer performance corporal orientada para o espaço e para o convívio público, há também uma clara intenção de identificar o corpo como processo e como obra.

Não se trata, aqui, de uma ação que poderia ser transferida, sem perdas de sentido, para o momento real, imediato, em contato com uma plateia. Ao contrário, são mesmo trabalhos que 
só podem existir da maneira que existem porque há a mediação da imagem capturada. No que diz respeito à temporalidade dessas obras - partindo-se do pressuposto de que uma performance só poderia acontecer no presente -, pode-se argumentar, ainda, que é justamente esse o efeito gerado pelo dispositivo fotográfico - ou um registro audiovisual: o eterno e constante deslocamento de uma ação passada para o aqui e agora.

É nesta chave que operam as obras de Helena Almeida. Seu corpo é a sede de suas relações com o mundo e o ato artístico é o seu campo de experiência e performação. Não à toa, em muitas de suas telas habitadas, Helena abandona o lápis ou o pincel e toca diretamente com as mãos as linhas e as manchas de tinta (ver Figura 2). Em outros trabalhos, as engole, ou, ainda, revela que sempre estiveram dentro de si, como um órgão ou a matéria interior de seu próprio corpo. Sobre o gesto de representar a tinta em contato com sua pele, Braz acrescenta:

As mãos - que estão presentes de diversos modos (...) frequentemente convocando e questionando a noção de pintor - desempenham aqui um papel importante, na medida em que permitem radicalizar a superação das oposições - entre interior e exterior, abertura e fechamento sustentadas pela ideia de limite. (2007, p. 54)

A tentativa de superação das dicotomias estanques entre corpo-obra, sujeito-objeto, interiorexterior, dentro-fora é compartilhada entre Helena e outros importantes nomes da arte contemporânea, como Lygia Clark - cujo trabalho a artista portuguesa poderá ter visto em Paris, no início da década de 1970, e no Brasil, quando expôs seu trabalho na Bienal de São Paulo, em 1979. As semelhanças entre os temas de seus trabalhos podem ser até mesmo identificadas pelos títulos de algumas obras: O dentro é o fora (1963), de Lygia Clark, e Dentro de mim (1998) ou Estudo para dois espaços (1977), de Helena Almeida; A casa é o corpo (1968), de Lygia, e A casa (1983) ou a exposição A Minha Obra é o Meu Corpo, O Meu Corpo é a Minha Obra (2015), de Helena. Entre essas duas últimas há, ainda, uma certa aproximação estética - o corpo que adentra o breu e o rasgo.

As ressonâncias entre os trabalhos de Helena e de Lygia não apenas comprovam o vínculo da primeira à arte performática como também denotam uma atenção a questões ligadas ao gênero e ao corpo feminino. Nas peças mencionadas acima, o uso constante da palavra "casa" parece evocar todas as conotações de domesticidade e feminilidade que 0 termo historicamente adquiriu - ao mesmo tempo que, no caso da artista portuguesa, também se refere ao ateliê como o espaço da arte por excelência, e, portanto, também tradicionalmente reservado aos homens. Em certa medida, suas obras são um grito de ocupação. 
A imagem do grito, da voz, é ainda mais explícita em séries como Ouve-me, de 1979, e Eu estou aqui, de 2005. Nesses trabalhos, Helena aparece, respectivamente, com os lábios "costurados" e ajoelhada, como que em um gesto de súplica e de sacrifício. A mancha vermelha que pinta sobre sua boca em uma dessas fotografias - que aparecerá com mais frequência, no lugar da mancha azul, em suas obras a partir dos anos 2000 - é, ao mesmo tempo, signo de força, de sangue - a visceralidade de seu protesto -, e de volúpia, desejo. 0 vermelho, aqui, pode ser entendido como uma alegoria do feminino.

Quando Helena opta por enquadrar suas pernas- signo da elegância e da sensualidade feminina - e obliterar seu rosto na série Seduzir (2002), está a mostrar a parte do corpo feminino que convém ao desejo do outro, está a colocar-se como objeto do olhar alheio. 0 erotismo - que também está expresso pelos saltos altos e pela saia - se descentraliza pelo corpo por meio dos desengonçados movimentos que Helena se captura a executar, deixando estampada a imagem do corpo de uma mulher a seduzir o espectador já, na ocasião, com quase 70 anos de idade.

Nota-se, portanto, que o trabalho da artista lusitana, com todas as camadas de sentido aqui detalhadas, surge e permanece na cena artística contemporânea porque suscita questões contundentes e relevantes para o nosso tempo - tanto no que diz respeito a reflexões internas ao campo da arte, como no que se refere a uma política dos corpos. Ao lado de outros grandes artistas de expressividade entre as décadas de 1970 e 1990, Helena Almeida apresenta aproximações e influências dentro e fora de Portugal. Mesmo assim, logra inventar uma linguagem totalmente única, nova e comovente, a ser ainda muito lembrada na História da Arte.

\section{Considerações finais}

A partir das questões apresentadas nesta pesquisa, pôde-se constatar que há, de início, um problema de definição que acompanha a produção artística contemporânea. Termos que antes designavam fazeres e técnicas específicas - "fotografia", "pintura" ou mesmo "performance", a princípio uma expressão mais abrangente - "caem por terra" e passam a não mais dar conta de traduzir os anseios e as tendências de nosso tempo. Quase sempre, essas modalidades de arte inéditas que surgem a partir dos anos 1960 - e continuaram a adquirir novos contornos até o início do milênio - são, na verdade, acusadas de assinalarem o fim da arte. 
Para Gullar (2003) e muitos outros estudiosos do campo, a demanda incessante pela novidade e a subordinação da obra de arte ao sistema mercadológico e empresarial - características típicas de um contexto capitalista e industrial de produção - seriam fatores decisivos para a desqualificação do que hoje se considera arte. Como mesmo a maior parte das teorias pósmodernistas que procuram explicar a instabilidade e o desamparo dos tempos atuais, os aspectos que nos descrevem passam, quase sempre, pelo negativo: não-original, não-estético e, portanto, não-arte.

Desde sempre, na História da Arte, foram esses os atributos que também definiram o fotográfico. Reduzida à condição de documento e marcada pela possibilidade ilimitada de sua reprodução, a fotografia - e, na sua esteira, também o cinema - raramente ocupa o espaço que merece ao lado da pintura, da escultura e outras formas clássicas de arte. É claro que a intenção deste trabalho não foi, de forma alguma, insistir no que seria uma inconvincente "equivalência" entre as tradições artística: levando-se em consideração apenas os fatores tempo e convenção, talvez a fotografia, enquanto invenção moderna e relativamente recente, ainda não tenha tido seu potencial completamente explorado (e teria a pintura?).

Trata-se, no entanto, de sublinhar sua importância para a arte. A partir da sua criação, tudo mudou, prática e conceitualmente: o sujeito, o objeto, o pictórico, a imagem, o poder e, sobretudo, o real ele mesmo. Não à toa Freud (1900), no livro que fundou a psicanálise, $A$ Interpretação dos Sonhos, compara o aparelho psíquico do ser humano a uma câmera fotográfica: a fotografia, com um só golpe, faz-nos duvidar da própria realidade: seria tudo apenas representação, apenas imagem?

No seio desta angústia - que é, mais uma vez, o sentimento de crise que tão fortemente nos circunda - está a busca pelo autêntico, pela carne desnuda e por tudo que consegue escapar ao esquema artificial da cultura. É preciso reconhecer, no entanto, que a arte, como um desses lugares que acolhem as ânsias e as inquietudes dos homens no tempo, participa da crise ao mesmo tempo que a desvenda. Há, na arte contemporânea, problemas formais e éticos extremamente originais, extremamente complexos, que se entranham e também se libertam de todos os tormentos sentidos individual e coletivamente. É, então, necessário que a positivemos: se, por um lado, se perde a certeza da arte, dos critérios estéticos, dos cânones institucionais, por outro, ganha-se um mundo de possibilidades.

Todas essas questões estão condensadas no trabalho de Helena Almeida - que, como é repetitivamente sustentado nesta tese, não se deixa definir inteiramente pela fotografia, pela pintura ou pela performance, muito embora todas essas formas de arte (e outras aqui não 
desenvolvidas, como o vídeo) sejam igualmente fundamentaisnas obras da artista. Está em jogo, novamente, a ideia de recusar os limites seguros e as fronteiras tão confinantes em prol de uma imagem e de um dispositivo inteiramente novo e singular.

Helena desestabiliza os papéis tradicionais que constituem a História da Arte, abandonando o específico para encontrar a "qualqueridade" - do pictórico, do corpo, da obra -, sem, no entanto, afastar-se do terreno da linguagem. Na verdade, é como se a artista portuguesa ressignificasse a ideia de representação ela mesma, através de uma gramática particular, inventada. Habita os "entres": um corpo entre a individualidade e o genérico, entre sujeito e objeto; uma fotografia entre o registro documental e a autoria artística; uma pintura entre a tradição e a subversão; uma obra entre o passado e o presente. Ao fazê-lo, lança luz sobre lugares da arte frequentemente obscurecidos, e nos convida a ocupá-los com ela

\section{Referências bibliográficas}

ALMEIDA, Bernardo Pinto de. Signos de uma escrita imóvel. In: A minha obra é o meu corpo. Catálogo organizado para exposição no Museu de Arte Contemporânea Serralves. Porto: 2015. ALMEIDA, Helena, ALMEIDA, Marta Moreira de e RIBAS, João. Uma conversa que não acaba. In: A minha obra é o meu corpo. Catálogo organizado para exposição no Museu de Arte Contemporânea Serralves. Porto: 2015.

BARTHES, Roland. A Câmara clara: nota sobre a fotografia. Rio de Janeiro: Nova Fronteira, 1984.

BENJAMIN, Walter. Pequena história da fotografia. In:Magia e técnica, arte e política: ensaios sobre literatura e história da cultura. $8^{\text {a }}$ ed. São Paulo: Brasiliense, 2012.

BRAZ, Ivo. Pensar a pintura: Helena Almeida (1947-1979). Lisboa: Edições Colibri, 2007. DUBOIS, Philippe. O Ato Fotográfico. 14ª ed. São Paulo: Papirus,2012.

GULLAR, Ferreira. Argumentação Contra a Morte da Arte. $8^{\mathrm{a}}$ ed. Rio de Janeiro: Revan, 2003. JEUDY, Henri-Pierre. O Corpo como Objeto de Arte. 2a ed. São Paulo: Estação Liberdade, 2002. MELIM, Regina. Performance nas Artes Visuais. Rio de Janeiro: Jorge Zahar, 2008. 